\title{
Heterotopia: Art Ephemera, Libraries and Alternative Space
}

Jacqueline Cooke

[This article is based on a poster session presented at the ARLIS/ NA Annual Conference in Houston, March 2005]

\section{Art Ephemera and Alternative Space}

This article is drawn from research in which I investigated the potential of a collection of art ephemera in a library to represent contemporary art practices which are otherwise rarely documented. Art ephemera are particularly likely to record transient and informal organizations and associated contingent strategies from the unstable and fugitive terrain of "alternative" art activities, which have been a vital part of contemporary practice. Their qualities, as art ephemera, give them a value as a source of potential histories which might otherwise remain obscure. I am most concerned in this project with art practices which are not objectbased, which are tactical and contextual, and in which the idea of alternative space remains operative. All of my examples took place in London, England, in the late 1990s. I am aware that both "alternative" and "alternative space" are contentious terms; I am using them to make practices visible and because the role of artists in validating art is both evident in ephemera, and is one of the diverse and contradictory aims on which this category touches.

Julie Ault's description and articulation of the issues relevant to the history of such diverse spaces and practices delineated in the essay "For the Record," published in Alternative Art New York, ${ }^{1}$ have been a central authority for me, although cultural differences between New York and London have become evident through my wider research. I decided to recognize the building of an art library collection as a representation of spaces, ${ }^{2}$ taking the artist-run alternative space as both material and theoretical space, and recognizing and exploiting the possibility that the library is a heterotopia, ${ }^{3}$ a place that contains different and sometimes contradictory understandings of the ideological spaces that we inhabit.

\section{Art Ephemera as Representations}

Art ephemera represent the art world in overwhelming detail when considered as a critical mass, although this picture remains partial. One way in which art ephemera do this is to map where events took place. I have developed this cartographical effect by including images of the sites and buildings where art events happened as part of the catalog database called Ephemeris. These images form a visual record of art sites in London during this period (1995-2005). The photographs were often taken when the building was closed, or became disused, or reused; they are in a sense empty and do not do what the ephemera sometimes do, i.e., communicate the intentions of the participants or document events. The collection with which I have worked is comprised of art ephemera from events taking place in London over ten years, from 1995-2005. I have organized this collection physically in chronological order, reflecting how ephemera arrive in the library as a day-by-day accumulation of items. I have indexed artists and all other named participants and gallery names for 1999-2001. Of necessity, ephemera in the library are usually considered in their plurality, kept in files. Such files are usually "artist files" and "gallery files" or "institutional files" which cluster the information under certain criteria, hiding other access routes and rearranging the ephemera's provenance. My hybrid of archival and library rationales is intended to increase the possibilities for access to this artificial archive. Such ephemeral and short-lived entities may not have archives in the conventional sense.

Julie Ault makes a strong case for ephemera as a resource. She says that "documentation of ephemeral events-protests, meetings, actions, installations, exhibitions, temporary art and items from the paper trails of short-lived groups-are least likely to be found in library collections and rarely circulate after the event." ${ }^{4}$ In setting up the collection, I was influenced by some exemplary collections of art ephemera that do include such materials and are relatively well known and accessible, such as the Political Art Documentation and Distribution (PADD) archive now in the library at MoMA, New York, and the Women's Art Library/ MAKE collection at Goldsmiths College Library. One motivation for setting up The Women's Art Library / MAKE collection was to make a kind of alternative space, a public place in which to document women's art. As in these examples, a partisan engagement can make a more cohesive collection. I am personally interested in how the idea of alternative space continues to operate, and in art that operates critically within informational forms; the examples I have chosen reflect these interests. The following account drifts from descriptions of particular places in London to representational space and informational space.

\section{A Particular Directness as a Resource}

Art ephemera have many qualities that make them a valuable resource. They have a particular kind of directness, being produced at the specific time by those involved. They may be used by the artist as an art form, as documentation, or to provide a context for the art. They may also be used to assert artists' professional authority on art, what it is, its place, and its role. In the introduction to the Life/Live exhibition catalog from 1996, which contains the most complete survey to date of artist-run 
spaces in London in the 1990s, Suzanne Pagé comments that "in addition to pursuing their own creative work, these artists also take charge of its distribution and communication, adopting a Situationist-style do-it-yourself approach." ${ }^{\prime 5}$ Art ephemera are usually freely or cheaply distributed, and this distribution is usually directly from the gallery or artist to the recipient. They are available in the context of an event; unlike publications, which are "broadcast," ephemera are usually "narrowcast" — sent in the mail, picked up at the event, or given by hand.

Figure 1, the poster "Proposed Redevelopment of the Oval, Hackney E2, London" - renamed: "Let the Blood of the Private Property Developers Run Freely in the Streets of Hackney Playscape Complex A," was folded to be mailed and was used as the announcement of an exhibition by Nils Norman held in a gallery near this street. In the poster, the simple clarity of the diagrammatic illustrations of an adventure playground replaced by new buildings counterbalance the fighting rhetoric of the title which blames private property developers. In a speech bubble, the message states that "the economic function of the local area has superseded the broader social function." This work relates to the artist's more extensive project ${ }^{6}$ to document all the public adventure playgrounds built in London, from their creation to their disappearance, and also to his other work in which proposals are produced for organizational change. In this case, the space exists, but the proposal is alternative.

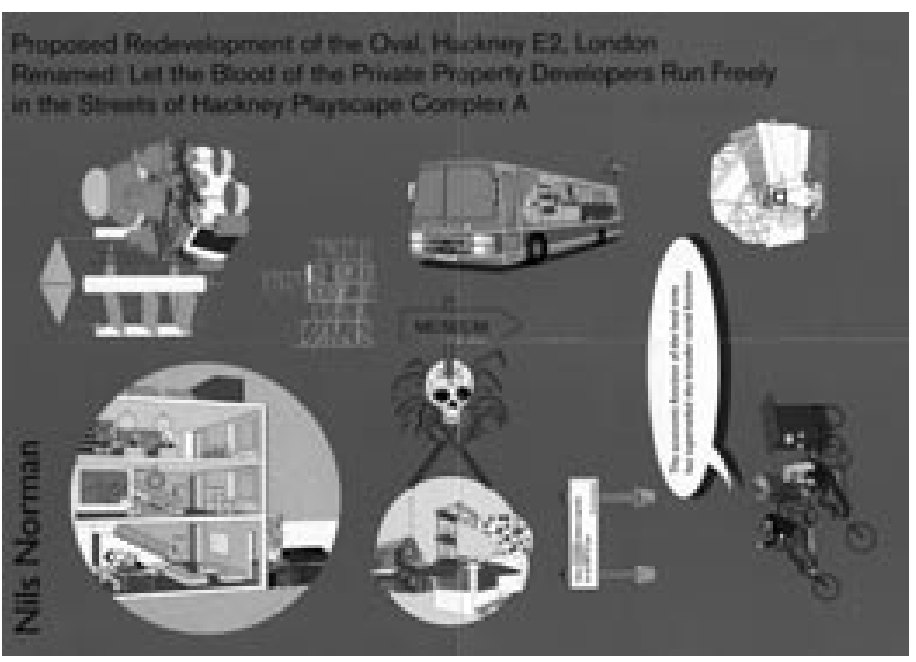

Figure 1. Nils Norman, Proposed Redevelopment of The Oval, Hackney E2. Poster/flyer. Courtesy of the artist.

\section{Documenting Transience}

A widespread definition of ephemera is that they are the "minor transient documents of everyday life." ${ }^{\prime 7}$ Art ephemera are the documents of the everyday activity of making art public. Art ephemera have a marginal yet dependent relationship to visual art. Their formats can be conventional; they are intended to act, for example, like a program for an event, but parody, homage, and pastiche are used to complicate, elucidate, or mix the messages. Text and images may accomplish this independently, or they may reflect or react upon each other. The visual element is as important as the textual, and the two cannot be understood separately, whether they are created by artists or not.

Art ephemera are especially valuable in a library collection because they document events and structures which are also ephemeral-the kind of events happening daily which form a large part of the art world, but which are often not commented on or written into published histories. Such events and institutions may later come to be considered as significant entities, or as failures, or just as a good day out.

A set of ephemera by Factual Nonsense (FN) was produced for a fair that took place outside the Festival Hall on London's south bank of the Thames, taking over a public space for the day. It was the second street market organized by $\mathrm{FN}$; the first had been the Bull Market in Lexington Street the previous year. The program lists about fifty artists who hired stalls and sold goods or services. In the evening there was a party in the Festival Hall. The set of ephemera produced for the event references some traditional formats. The program references the format used for a parochial agricultural fair in its textual and image content; the fonts and layout are traditional and ornate. The sheep is used as the central illustration, and this image is redeveloped at the bottom where two sheep are shown, each standing with one foreleg raised, facing each other. The denomination of the fake currency note is "One Sheep" (Figure 2). This currency was bought or exchanged for pounds sterling, and the Sheep were then spent in the market. They serve both as what they conventionally are and also as souvenirs of the event.

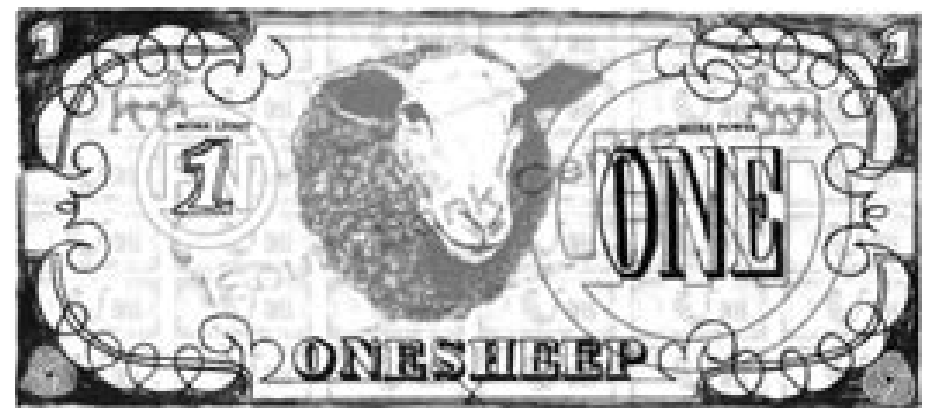

Figure 2. Factual Nonsense, One Sheep Currency Note, 1999. Courtesy FN.

\section{Altering Conventions}

Art ephemera may have brief and conventional content, or they may be very condensed, elaborate sources of information. Contemporary art ephemera often use visual and textual strategies which relate to the event and to social and political intentions; they also allude to traditional styles of ephemera by using citation, parody, or mimicry, as in the example from the Agricultural Fair. In art ephemera, such strategies and tropes are used to document and question the interrelationship of the terms of art and the terms of its place in the world. The use of logos and series to identify institutions and organizations is a convention of publicity material. The existence of such conventions means that these conventions can be used, creatively and critically, to comment on the event and the institution, and to describe tactical uses of such cultural forms. Although ephemera often exist in the form of logos and series because of a need to set out ideas or to communicate in a very contemporary time frame, the categorization of the manifestation of the material should not dominate our understanding of its meaning. Ephemera are usually intended to be useful for a short time, and it is this usefulness that is literally ephemeral, rather than the items themselves; these often become souvenirs, or are intended as documentation.

Because it is made in advance of an occasion, an ephemeron may be evidence that something existed. Anna Best's leaflet for "Occasional Sights: A London Guidebook of Missed 
Opportunities and Things That Aren't Always There" (Figure 3) documents possibilities, rather than certainties. She used the line of the Thames to indicate London, and in the leaflet she names places and sights which are occasionally present. She states, "I gathered anecdotes, images, drawings and some interesting encounters and made a book, like a guidebook that works alphabetically by area, but almost an anti-guidebook in that many other things wouldn't be there if you went back to

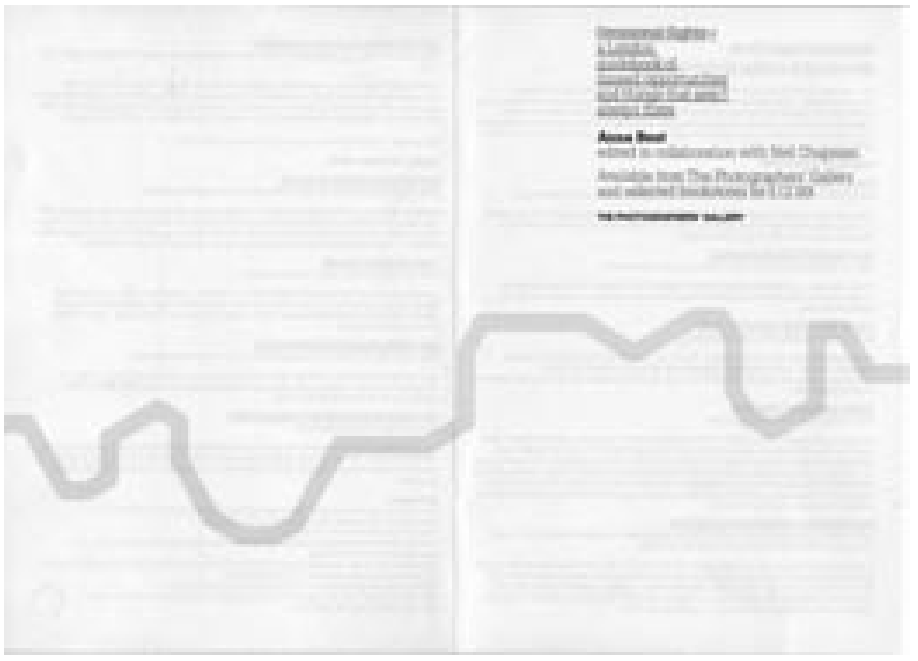

Figure 3. Anna Best, Occasional Sights. Leaflet. Courtesy Anna Best.

find them. I also didn't want the book to be seen as the end of the project, something too final, but a tool to use to explore London, or anywhere in fact, in a different way." 8

Alternatively, the ephemera may document a work which was an installation, where the space was as represented, but it was not possible to experience it. The image in Figure 4 comes from an item produced by Salon 3 to announce and document the exhibition Irrigation-Fertilisation by Bojan Sarcevic at the gallery. The artist flooded the floor of the Elephant and Castle Shopping Centre on a Sunday night. The leaflet is a single sheet of paper, folded for mailing, with an image covering one side and text in a band along the bottom that gives information about the exhibition. The leaflet is cheaply produced, one-color printing on thin paper, combining exhibition announcement and a representation of the work in one piece. The artist reflects on the site of the gallery, in this work.

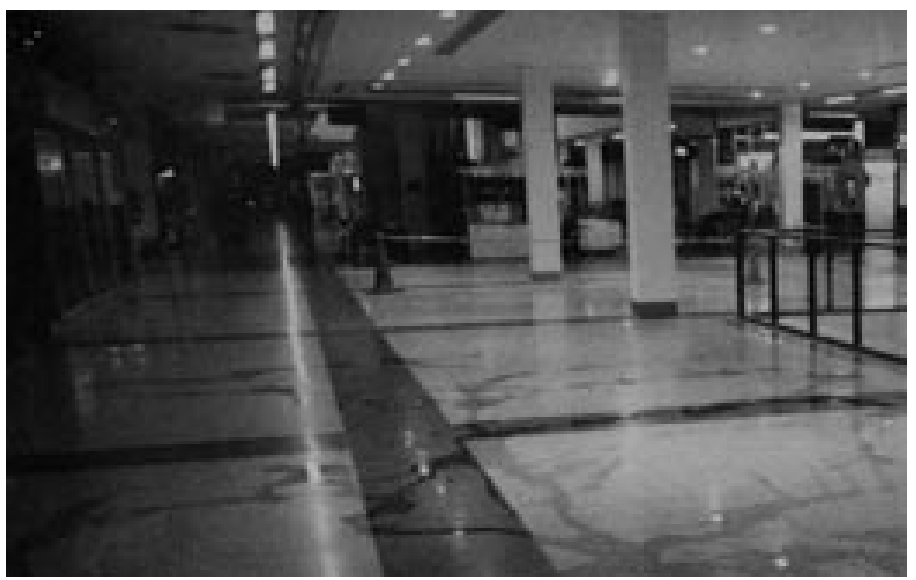

Figure 4. Bojan Sarcevic, Irrigation-Fertilisation, London: Salon 3, 2001 [detail]. Courtesy Salon3.
Salon 3 was established by Rebecca Gordon Nesbit and Hans Ulrich Obrist in unit 318 in the shopping center. A non-commercial gallery run by professional curators, it was funded with grants from public funding bodies. The gallery was in an alternative location where few other galleries and art projects were found. The shopping center was not thriving, and the shops there were very low budget. Many units were empty, which is why the gallery could exist there on low rent. The shops in the center sold substitutes and cheap goods; the center was maintained by the local council, and at that time was painted pink outside. This use has nothing to do with shopping. Shopping centers are sheltered and warm, to make spending time in them more pleasant. This image makes the unit appear desolate and decaying, but the shiny rivulets are pretty. The artist's opinion of commercialism and commodification as such is not spelled out. An experimental rather than a didactic work, it temporarily takes over the space for a different purpose.

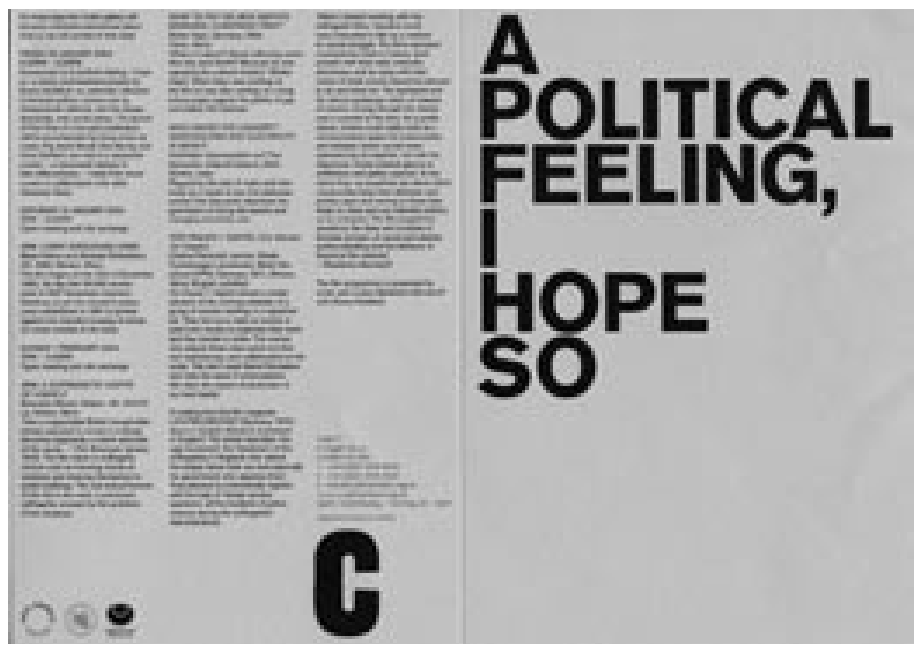

Figure 5. Emma Hedditch, A Political feeling, I Hope So. 2004. Courtesy E. Hedditch.

\section{Creating Institutions}

Ephemera may also be used to describe the taking over of a space in a more ideological way, as in the example "A Political Feeling, I Hope So" (Figure 5). This is a card announcing a weekend of events at Cubitt Gallery in Angel Yard, organized by Emma Hedditch. She places her subjective self into the statement where she conjoins politics with feeling and hope, and a statement with intention. On the reverse side, the text begins "For three days Cubitt Gallery will become a feminist autonomous space...at least we will commit to that idea." She has taken herself to the space, temporarily replacing its own institutional identity. The phrase "at least we will commit" is what for me describes the complexity in this example; it acknowledges distance, without lessening the integrity. The "we" is fluid: there are different participants in the different events. Cubitt as an institution has made this change of space possible. Cubitt is both artists' studios and a gallery, run by a changing committee of studio holders, with shows organized by guest curators for a fixed period.

Cubitt temporarily hosted a different institution for the exhibition Publish and Be Damned, curated by Emily Pethick and photographed in 2004 (Figure 6). The show was a collection of artist-published magazines which were displayed on tables and pegged on lines, and therefore available to be read. There is a shift 


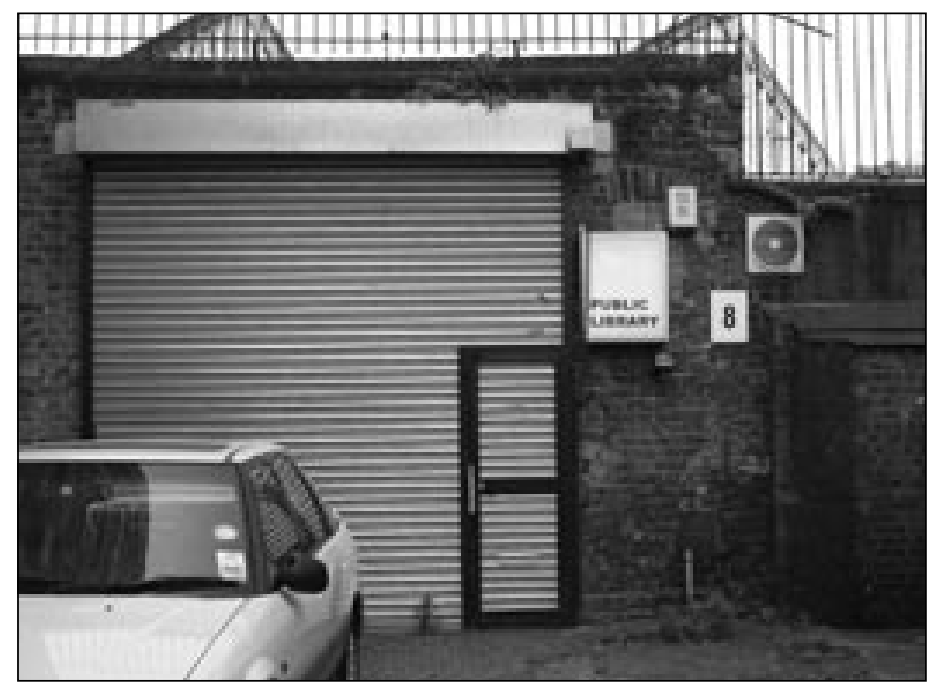

Figure 6. Cubitt Gallery, Angel Yard, 2004, with sign for "Public Library." Courtesy Ephemeris.

here from material space to considering the form of the institution as the work. The building itself was labeled with a notice-Public Library-to temporarily change the identity of the space.

Cards for some galleries show clear institutional identity, particularly those that are conceived as series, in which the design emphasizes the institution. The cards for Platform Gallery were designed by Secondary Modern and look like train tickets (Figure 7). The gallery is run by Sheila Lawson, and she describes it as a non-commercial project space. Neither she nor the designers are named on the cards. Platform - the institution-is presented as a series of platforms for artists' shows.

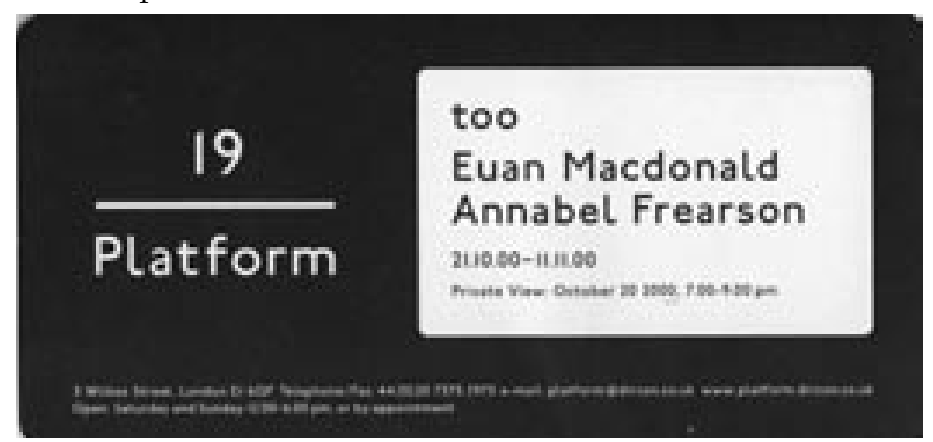

Figure 7. Platform, Exhibition Announcement Card. Courtesy Platform.

Info Centre was a project that Henriette Heise and Jakob Jakobsen ran from 1999-2000 in London. During that time, they produced six issues of a newsletter and invitation cards for events in a consistent format. Conventionally, the production of coordinated printed materials focuses on the institution rather than the individual. However, the personal style of communication in the ephemera reflects the "self-institutionalization" that was stated as an aim of the project, as did the location of the space in their home flat.

The process of institutionalization has often been seen as a problem, something that runs counter to the original aims of artists who set up artist-run organizations. ${ }^{9}$ However, rather than seeing institutionalization as an outside process, Info Centre takes it on as the context of the work, something that can be worked with, rather than as a threat; such nuance is innovative in this project. The design of its ephemera contributes to the Info
Centre's artists' idea of the way this particular institution works. Figure 8 shows an announcement of an art event combined with a social invitation to have a drink. A last newsletter explains the end of their self-institutionalization and their strategic exit from that space:

\begin{abstract}
At Info Centre we are, as many others are, working on exit strategies and ways not only to invent, but to get access to new fields of possibilities for thinking and acting and means to establish new grounds for the flows of desires and wills which can't be channeled under the present mental and material circumstances. Just the idea of an exit makes us imagine things. But it isn't always that straight forward to make an exit and often they fail. You have to run the risk.
\end{abstract}

We are off. ${ }^{10}$
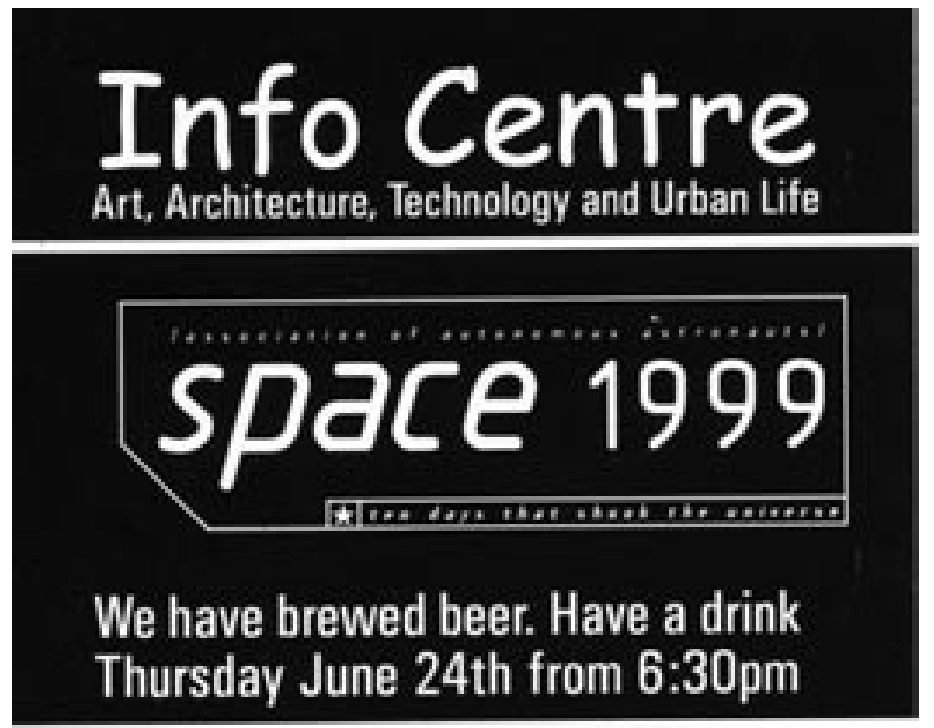

$$
\text { See you in space }
$$

\section{Top Floor, 123a Mare Street, London E8 3RH, TiF 01819859981}

Figure 8. Info Centre, Space 1999. Invitation Card. Courtesy H. Heise.

\section{Addressing Contexts and Criticality}

Despite critical strategies, the institution of art itself continues. In addressing the problem of how to be critical, in relation to art in its wider context, the form of ephemera itself, as a conveyer of information or knowledge, is sometimes used reflexively. Ephemera are used intentionally to alter the context of an event, to mediate how the particular institutional space affects the art. Sometimes the work itself is concerned with tactical use of informational forms, in which case, the critical context of the alternative is that in a knowledge economy-where creative thought, knowledge and information are important factors in how the economy functions - the problem of how to be critical becomes more complex. ${ }^{11}$ Art ephemera are used as a critical space.

Johnny Spencer's "Inquiry Unit" (Figure 9) was commissioned as part of the show Century City at Tate Modern in 2000. 


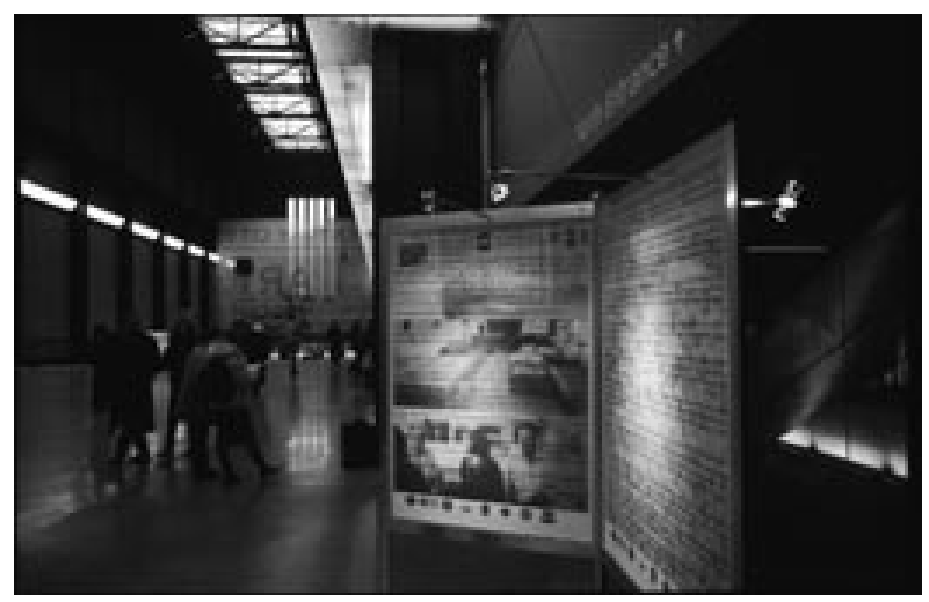

Figure 9. Johnny Spencer, Inquiry Unit. Century Cities, Tate Modern, 2000. Courtesy the artist.

The work was in the form of a set of corporate-style information panels that had begun to appear in museums and galleries to mediate or contextualize the art works in an exhibition. The text on the panel was the result of an inquiry into the state of current thought on art and its relationship to the knowledge economy. At the artist's request, the work was not documented as being part of the exhibition, although it was listed in the catalog. In the context of the exhibition, it appeared at first sight to come from the institution. However, on reading it, it did not have an institutional style-it was far more opinionated, and it was critical of the prevailing institutional presentation of art as a constituent of a "culture capital" in 1990s London. ${ }^{12}$

\section{Art Ephemera in the Library}

The site or context of art ephemera affects how the ephemera function. Library collections contain material that is de-contextualized, which we re-contextualize by the way we arrange, describe, and provide access to it. ${ }^{13}$ Art ephemera collected by libraries are usually stored in artist files or institutional files. If these are cataloged in our main catalogs, they are usually accessed under the names of the artists rather than arranged thematically. This procedure is very useful and does help to provide access to the files-both through the artist's name and with the aid of online bibliographic indexing and abstracting services-to artists who work in particular ways or who deal with specific subjects. Name indexes of artist files have also been expanded to form bibliographic resources, and once readers know about the files, they have access to a more varied source material, including artists' statements as well as cuttings from a wider range of publications. One result of this practice, however, is to emphasize the role that ephemera have as evidence of events in the careers of individual artists.

Ephemera have many roles, as I have described above; they may be immediately useful at an event, they may act as an invitation, or like "Inquiry Unit," they may be critical in the context of an event. Ephemera may provide evidential information or documentation about the event or the activities of participants after the event is past, or may represent an event in an archive. Archives of galleries and organizations, as well as of individuals, often contain ephemera, in which case the structure of the archive provides an alternative context for the ephemera that emphasizes its relationship to exhibitions, events, or projects or to the aims of the organization. In a similar way, collections may have a particular focus, and catalogs may be used to reflect the ideas represented in ephemera. In 2002 I took part in Vektor, ${ }^{14}$ a project that investigated the possibility of a joint catalog for European archives of contemporary art held in archives, galleries, and libraries. As part of the project, we compared subject headings that we used locally with those in the Art and Architecture Thesaurus (AAT), and in discussion we found that we needed more definition of contemporary curatorial strategies and a better definition of art that was more concerned with social processes than are customarily found in library catalogs that use existing standards.

Ephemera convey the visual and textual strategies of their times. They are a condensed source of information; they may be innovative, but often tend to cite or re-use conventional communication strategies. In some ephemera, documentation or representation of the work for the archive and the work itself might be indistinguishable, both conceptually and in format. The catalog may be used to create relationships between parts of one item or groups of material. Artworks, documentation of art, and administrative documents may be interrelated, and the catalog can be used to make those relationships evident. Using hierarchical structures such as those made possible by Functional Requirements for Bibiliographic Records (FRBR) ${ }^{15}$ or cross-references, this structural principle can be applied when cataloging digital ephemera, or ephemera related to recordings of art practice. Ephemera are individually fragmentary, and possibly incoherent as source material. If library practices can be used to re-contextualize them by drawing out the relationships that ephemera have to other ephemera, or to other materials, or to art practices and ideas, then that will help to draw out their potential as sources.

The different ways that ephemera function may consequently affect their meanings. To some extent, this is always the case, but when the ephemera are used to comment on the original site or context, then the move into a library collection may substantially affect the meaning of an ephemeron. The following example is an excerpt from the remarks of Dick Burn, former Medea Group (an advanced multimedia company) coordinator, at Marilyn Community College in Calais, France, on June 18, 2001. An information panel with the text was shown in the exhibition The Communications Department ${ }^{16}$ at Anthony Wilkinson Gallery. The text was also produced as an exhibition handout on a single sheet of paper. The part of the text I cite here reflects upon the value of knowledge:

One problem with knowledge is that it can get obsolete quickly. Here again, groups like Medea look to partners like Marilyn Community College to remain vigilant in keeping students abreast of changing trends and developments. We need people that can quickly take inventory of what they know and see the strategic landscape as well as the details. They can jump on something and withhold it, gaining substantial political advantage. ${ }^{17}$

The meaning of the text in the copy in the library collection is changed in this example by its context, rather than by the physical differences (in size, position, etc.). The text does not contain a reference to the Communications Department show to carry that context with it. Neither is the artist identified, so in this case the dynamic of the particular event is lost. What does remain 
is that the text indicates that criticality, argument, dialectic, and mapping produce knowledge, and that consequently these tools which were developed in opposition to dominant ideology are now useless against it. As Johnny Spencer, one of the artists, explains: "It just so happens that for the last decade my art has been a combination of those things that are central to the immaterial worker: knowledge, information, affect, communication, and ideas. Dematerialization was itself now central to the neo liberal/global capitalist vision of the future..."18 However, my reading of this ephemeron as deposited in the library is that it functions tautologically with the text, as a withholding of knowledge - a complex alternative strategy.

\section{Conclusion}

All of the art practices described in this essay work in some way with the context of art, trying to find ways to be critical. Using parody, detournement, and heartfelt idiolectal diatribe, they use ephemera as the carrier of their voices as artists to question the space of art. This resource enhancement project became partly an investigation into art practice and the idea of alternative space, but it is mainly an investigation into how an art library can support and document research in contemporary visual art practice, in which I tried to understsand some of the issues of context and representation across both art and librarianship. I have been working as visual arts and special collections librarian at Goldsmiths College, University of London, concurrently with conducting the research supporting this article and have used the material collected to develop a working resource. ${ }^{19}$ The resulting catalog Ephemeris was developed as a database using FileMaker Pro, with Dublin Core metadata. It is arranged chronologically and indexed intensively. My intention was to use cataloging processes with a small collection as a research tool to investigate the potential of ephemera as a research resource, rather than to produce a system which in turn may be expanded for use with a larger collection. Ephemeris is available in the Special Collections Department at Goldsmiths College and will soon be made available online. ${ }^{20}$

\section{Notes}

1. Julie Ault, "For the Record," in Alternative Art New York (Minneapolis: University of Minnesota Press, 2000), 1-16. Julie's opposition to the term "alternative," etc., is that "these terms inscribe and promote a hierarchical understanding of the art field as a system." Her position is that "For the sake of visibility and clarity, I find 'alternative' to be useful as a general term because it declares historical and critical relations between the structures thus classified and the then existing institutions and practices." (pp. 3-4). I have adopted this view here.

2. Based upon Lefebvre's analysis of different kinds of representational spaces. See Henri Lefebvre, The Production of Space (Cambridge, MA: Blackwell Publishers, 1991).

3. Michel Foucault, "Of Other Spaces," in Architecture Culture, 1943-1968, ed. J. Ockman (New York: Rizzoli, 1993). Foucault proposes the library specifically as a heterotopia of time, rather than space.

4. Julie Ault, "For the Record," 1-16.

5. Suzanne Pagé, preface to Life/Live, vol. 1 (Paris: Musées de la Ville de Paris, 1996), 8.

6. Nils Norman, Keith Cranwell, and Paul Claydon, An Architecture of Play: A Survey of London's Adventure Playgrounds (London: Four Corners Books, 2003).
7. Michael Twyman, introduction to The Encyclopedia of Ephemera: A Guide to the Fragmentary Documents of Everyday Life for the Collector, Curator and Historian, by Maurice Rickards (London: British Library, 2000). Twyman here states that "among several definitions of ephemera that Maurice Rickards proposed, this is the one that has gained widest currency."

8. See http:/ / www.annabest.info/cx occasional-sights/ index.html. There is also a related book: Anna Best and Neil Chapman, eds., Occasional Sights (London: Photographers Gallery, 2003).

9. See, for example, the theme issue "The Visual Artists' Organization," Afterimage 14, no. 3 (October 1986), in particular Judy Moran and Renny Pritikin's article "Some Thoughts: Artists Organizations Contrasted to Other Arts Organizations," pp. 9-17.

10. Info Centre, excerpt from 6th (final) newsletter, 2000.

11. Johnny Spencer, "We Know Too Much These Days," http://www.infopool.org. Spencer reflects that "As Donna Haraway reports in the Cyborg Manifesto, as long ago as the Macy conferences in 1946, humans were to be seen as information-processing entities who are essentially similar to intelligent machines. It's the information flows that count."

12. Emma Dexter, "London 1990-2001: Picturing the City," in Century City: Art and Culture in the Modern Metropolis (London: Tate, 2001), 72-95.

13. I treat the subject of cataloging as re-contextualization only briefly and theoretically here. In my article "Calling in the Dark: Identifying Our Ephemera Files" (forthcoming, Art Libraries Journal, Autumn 2006) I have reviewed practical models of cataloging ephemera in relation to this theme, and I am continuing to research in this area. My case is built on anecdotal evidence from colleagues in the U.K. and the Vektor project, and from curatorial use of ephemera in exhibitions such as Alternative Art New York, Extra Art, Interarchive, Bankside Browser, and Bring the War Home.

14. Lioba Reddeker, ed., Archiving the Present-Gegenwart dokumentieren: Manual on Cataloguing Modern and Contemporary Art in Archives and Databases / Handbuch zur Erschließung moderner und zeitgenössischer Kunst in Archiven und Datenbanken (Vienna: basis wien, to be published 2006); details from http:// www.vektor.at.

15. See OCLC Research Activities and IFLA's Functional Requirements for Bibliographic Records, http://www.oclc. org/research/projects/frbr/.

16. The Communications Department exhibition took place at Anthony Wilkinson Gallery, London, June 2001, and was curated by Alex Farquharson. There was no catalog.

17. Medea Group, remarks of Dick Burn, 2001.

18. Johnny Spencer, "We Know Too Much These Days."

19. I am grateful to Goldsmiths College Visual Arts Department, University of London, for supporting the project, both academically and with a small research grant. My forthcoming $\mathrm{PhD}$ dissertation will be called "Art Ephemera and Alternative Space in London 1995-2005" and is due to be completed in 2007.

20. See Goldsmiths College Library Special Collections Web site at http:/ /libweb.gold.ac.uk/speccoll.php.

Jacqueline Cooke, Subject Librarian for Visual Arts \& Visual Cultures, Goldsmiths College, University of London (UK), j.cooke@gold.ac.u 